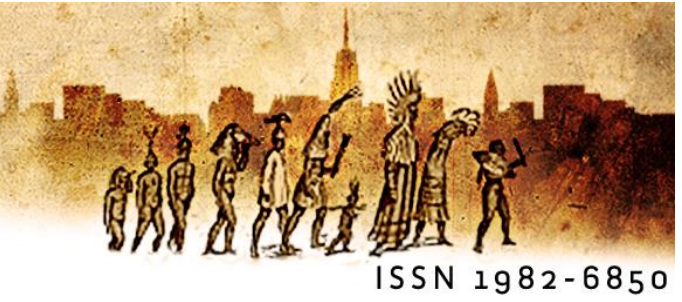

\title{
Don Quijote y Max Estrella: dos caballeros, una misma bandera. (Elementos y argumentos para una relectura quijotesca de Luces de bohemia)
}

Juan Ignacio Jurado Centurión Lópezi (UFPB)

Resumen: La representación más icónica que nos ha quedado hasta hoy del escritor Ramón María de Valle Inclán es sin duda la que le retrata con su larga barba, su rostro afilado y su delgadez extrema, como se puede ver en la estatua del escritor gallego situada en la madrileña calle de La Castellana, muy cerca del Café Gijón, lugar que solía frecuentar el autor. Esta imagen, a su vez, nos remite irremediablemente a la descripción que Miguel de Cervantes realiza de su personaje más célebre e inmortal: Don Quijote de la Mancha. Y va a ser esta peculiar semejanza la que situé el punto de partida de nuestra arriesgada argumentación. En las próximas páginas, a través de citas literarias de estas dos obras capitales de la literatura española y del pensamiento de algunos renombrados críticos, vamos a observar una serie de aspectos que nos ayudarán a hacer una relectura quijotesca de "Luces de bohemia" y esperemos que nuestros argumentos sean lo suficientemente sólidos para que esta reflexión no sea tan solo una quijotesca lectura, producto de una forzada exegesis y fuera de tono.

Palabras clave: Cervantes; Valle Inclán; Luces de Bohemia; Don Quijote; Imperio Español.

Abstract: The most emblematic representation that remains actually of the writer Ramón María de Valle Inclán is certainly the one that portrays him with his long beard, sharp face and extreme thinness, as seen in the statue of the Galician writer located in the street of Madrid of La Castellana, very near of the Café Gijón, place that the author used to attend. This image, in turn, leads us irremediably to Miguel de Cervantes's description of his most famous and immortal character: Don Quixote. And it will be this peculiar similarity that puts the starting point of our risky argument. In the following pages, through literary quotations from these two great works of literature and the thought of some renowned critics, let's look at a number of aspects that will help us make a quixotic rereading of "Lights of Bohemia" and hope that our arguments are solid 
enough that this reflection is not just a quixotic reading, the product of forced and out of tune exegesis.

Keywords: Cervantes; Valle Inclán; Luces of Bohemia; Don Quixote; Spanish Empire.

Era de complexión recia, seco de carnes, enjuto de rostro.

(Don Quijote de la Mancha, Miguel de Cervantes)

\section{Introducción}

Para comenzar nuestra atemporal travesía hacia el mundo literario de estos dos autores vamos primero a conocer el contexto histórico y social que le tocó vivir a cada uno de ellos. Esta aproximación nos ayudará a encontrar algunos elementos en común que los dos escritores comparten y que se revelan en la difícil tarea de intentar catalogar una obra como Luces de bohemia.

\section{Un imperio español, del principio al fin}

Como ya hemos reiterado en muchas otras ocasiones, la historia y sus momentos, sus periodos concretos son definidos en la mayoría de las ocasiones mucho tiempo después de que estos hayan ocurrido. Con el objeto de facilitar estos periodos dentro del cont inuo acontecer de la humanidad, a lo largo de su trayectoria se forja una controvertida cronología que, si por un lado ordena el tiempo y con ello muestra unas realizaciones artísticas para su fácil reconocimiento y estudio por las generaciones venideras, por otro lado, el encasillamiento de estos momentos en unos compart imentos estanco, que como advierte Cornejo Polar (1999) niegan las posibles simultaneidades, facilita otro aspecto más perverso; el desorden y principalmente la muchas veces errónea atribución de una serie de característ icas estereot ipadas a cada uno de estos periodos y por extensión a los protagonistas de este periodo que ahora se presenta enclaustrado en las páginas de un manual de historia. Algo muy parecido a lo ocurrido con la neurosis colectiva que, en las últimas décadas, ha suscitado el estudio y la necesidad de definir una determinada identidad nacional. Ambas preocupaciones limitadoras terminan, si no se tiene mucho cuidado, por hermet izar el pensamiento y nuestra propia esencia y crear dubios dogmatismos que aunque quedan muy bien en los ya referidos manuales escolares e incluso en los universitarios, 
no quedan tan bien si nos paramos a pensar, de modo pragmático, en lo que realmente significaron en su contexto y en los días de hoy esos momentos históricos y sus protagonistas.

Después de esta breve reflexión, podríamos observar que, desde la academia sería fácil enmendar esta problemática, legado infame de una tradición positivista y ordenadora. Dicha solución pasaría por desatascar los oxidados conductos de nuestras historiografía y su dudoso cronograma y plantear otras alternativas a la hora de examinar el camino que la humanidad ha llevado desde que el ser humano levantó su mano para pintar en las paredes de una cueva rupestre hasta que bajó su cabeza para insertar su más reciente ocurrencia en las hipotéticas páginas de un aplicativo de su móvil. Pero no nos vemos en condiciones, por las limitaciones impuestas en este breve artículo, de abordar algo tan impresionante como es el transcurso histórico de la humanidad y sus posibles representaciones.

Tímidos en nuestra intención, prácticos en nuestra reflexión y principalmente objetivos a la hora de acercarnos al objeto central de nuestra deliberación, vamos a tomar prestado el pensamiento de Anthony Compagnon para dar continuidad a nuestra idea:

\begin{abstract}
Mais restritamente ainda: literatura são os grandes escritores. Também essa noção é romântica: Thomas Carlyle via neles os heróis do mundo. O cânone clássico eram obras-modelo destinadas a serem imitadas de maneira fecunda; o panteão moderno é constituído pelos escritores que melhor encarnam o espírito de uma nação. Passa-se, assim, de uma definição do ponto de vista dos escritores (as obras a imitar) a uma definição de literatura do ponto de vista dos professores (os homens dignos de admiração) (COMPAGNON, 2003)
\end{abstract}

La ascensión de determinados artistas al panteón de los dioses y la consolidación discutible del canon occidental de Harold Bloom (1979) forjaron y aun forjan una visión de aquello que debemos considerar el culmen de la creación literaria. Y como debatible que es, podemos considerar que, como observa el propio Bloom, el canon existe porque no tendríamos literalmente tiempo de leer toda la creación bibliográfica de la humanidad y es preciso que exista una delimitación impuesta 
aunque ésta pueda suscitar tanta controversia Solo eso just ificaría la existencia del canon, pero no la subida al pedestal.

Pero volvamos ahora al asunto que nos concierne para evitar distanciarnos de este y caer en infinitas e infructuosas aporías que terminarían por aburrir a nuestro lector. Como observamos líneas encima, uno de los puntos en común que hermana a nuestras dos obras objeto de reflexión, a pesar de la distancia temporal, es sin duda la presencia de ambas obras dentro del contexto de una España imperial que, si en el momento de publicación de la primera, iba poco a poco consolidando su poder sobre el vasto territorio que ocupaba, en el caso de la segunda, la decadencia y la pérdida de su hegemonía era ya un hecho consumado. Será este contexto histórico el que abra nuestra discusión, sin embargo la presentación y el análisis de otras notorias coincidencias entre estas dos geniales creaciones literarias nos servirá para dar cont inuidad a nuestra deliberación.

\section{El grupo del 98, la luz de la sombra}

Circunscritos por los historiadores literarios dentro de lo que se ha venido a Ilamar la Generación del 98, este ecléctico grupo de intelectuales supo, como pocos, reflexionar, unas veces desde la estética, otras desde la literatura y otras desde la filosofía, sobre los tiempos conturbados que les tocó vivir, y aunque tradicionalmente se ha querido disociar este grupo generacional del contemporáneo movimiento artístico conocido como Modernismo, hoy en día no es fácil aceptar este corte histológico entre estas dos maneras de enfrentarse intelectualmente a la difícil situación social que enfrentaba la España de finales del siglo XIX. Los dos movimientos artísticos rechazaban abiertamente el período que les había tocado vivir y pugnaban por una renovación en su sent ido más amplio: renovación, política, social, religiosa y claro, como no podía dejar de ser, en el aspecto pedagógico. Pensadores de la talla de Giner de los Ríos, Joaquín Costa, Antonio Machado o Valle Inclán, entre muchos otros, instigaron desde sus diferentes campos de actuación ese deseo renovador que alteraría inevitablemente el rumbo que España iba a experimentar durante el siglo XX. 
Es más que obvio que los escritores que suelen clasificarse como modernistas o como noventayochistas viven su juventud y primera madurez en el centro de una época que va, digamos, de 1875 a 1914, es decir, la época de la gran "Paz" imperial europea hasta su primer conflicto armado interno. Y es también claro que la confusión acerca de si son o no la misma cosa 98 y modernismo responde a que, según hemos dicho, unos y otros conviven y coproducen a partir de los años noventa del siglo pasado. No hay, pues, duda con respecto al hecho de que los llamados modernistas y los llamados noventayochistas, como por ejemplo valle Inclán, son escritores de una misma época en la cual, al parecer, comparten los mismos problemas y la misma actitud ante los valores heredados. (BLANCO AGUINAGA, 1979)

Fuese un movimiento, fuese más de uno, el pensamiento finisecular y sus resultados, según la historiografía más tradicionalista, sirvieron de colofón a uno de los más importantes periodos de la historia moderna del país: el imperio español. Considerados como marco de inicio de esa trascendental etapa, la llegada y el posterior descubrimiento de unas, por lo menos para el cont inente europeo, nuevas tierras, las cuales con el pasar de los años serían denominadas como América, abrieron para Europa y principalmente para una España que poco a poco se iba unificando, uno de los momentos más importantes de su historia. Aunque la trascendencia de este episodio, como afirma Elliot (1979, p. 41) no fuese considerada en su momento tan importante y solamente siglos después el mundo iría a descubrir plenamente la importancia del mismo:

El Nuevo Mundo, tal como fue concebido por los europeos de finales de la Edad Media y comienzos del Renacimiento, no era más que una imagen mental. Los conquistadores, que habían sido impulsados por su afán de riquezas, tierras e hidalguía, contemplaban con desencanto como los funcionarios de la corona española les invadían su paraíso feudad. (...) Hacia la mitad del siglo XVI, las discrepancias entre la imagen y la realidad no podían seguir siendo sistemáticamente ignoradas.

Sin embargo, tuviese o no, este lugar desconocido y exótico, en su momento, la relevancia que hoy la historia le quiere dar, lo que no podemos obviar es que el fortuito encuentro de estos dos mundos singularizó el planeta y fue el punto de partida para iniciar un nuevo orden mundial y así se convertirá en el germen de diversas manifestaciones, tanto en el campo de las relaciones sociales, como en el de 
las económicas. Como advierte Todorov (2007), el descubrimiento de América cambiará drásticamente la realidad de los dos cont inentes directamente implicados y por extensión la de los otros tres. Incluso de la propia Oceanía, cont inente que solo pudo ser descubierto en 1770 gracias a los avances tecnológicos provocados por el auge de las navegaciones ultramarinas que se produjo tras la aventura colombina.

Es en ese marco histórico, conocido como Siglo de Oro y dividido entre la gloria de tiempos pasados, la visión mesiánica de unos monarcas obsesionados por la unidad religiosa de la cristiandad y la miseria de la mayor parte de la población, es en el que nace una de las creaciones literarias más importante de todos los tiempos y según se acostumbra a decir; el segundo libro más leído después de La Biblia. La historia, según dice su autor: poco presuntuosa y más seca que el esparto, nos presenta, a partir de su capítulo séptimo y de la segunda salida del caballero andante a la pareja más célebre y singular de toda la literatura moderna. Algunos críticos han querido ver en estos dos personajes la esencia del alma humana, el complemento ideal de cada uno de nosotros: la visión idealizada del mundo y la visión práctica. Si todos tenemos sueños, todos sabemos, lo reconozcamos o no, que es necesario mantener los pies en el suelo para poder alcanzarlos. Pero a pesar de la importancia de esta reflexión y las muchas páginas que podríamos rellenar debatiendo sobre el asunto, incluso, como diría el propio Cervantes, regalando al lector importantes citas de autores clásicos, quién sabe de filósofos griegos y latinos desde la a hasta la z del diccionario, no es nuestra intención hacerlo y no es nuestro deseo cansar tan temprano al lector.

Observamos más arriba la importancia literaria y extraliteraria de esta singular pareja que, con el fondo de un prolongado diálogo, género tan de moda en esos tiempos humanistas, nos lleva de la mano en su singular paseo para conocer de primera mano los aspectos más diversos de la condición humana. Sin embargo, más allá de la visión esencialista de dicha condición, Quijote y Sancho representan una realidad mucho más próxima al contexto que les tocó vivir y sus diferentes visiones de mundo reflejan perfectamente los bastidores de ese imperio español que hasta hoy nos seduce por el aluvión de episodios gloriosos que los historiadores más conservadores se empecinan en catalogar en métodos didácticos o historias de España al uso. La memoria histórica sigue siendo muy selectiva por mucho que se 
esfuercen unos y otros. Así, caballero y escudero son, en la visión de muchos exégetas, el espejo fiel de la España imperial, de su historia más conservadora y hasta hoy Cervantes nos sirve de parámetro para, a través de estos dos personajes, podamos imaginar los bastidores por detrás de ese prolífico período de la historia española. No tenemos aquí la pretensión de dar desmedidas alas a nuestra imaginación o querer dar munición a los que hasta hoy alimentan la tradicional y controvert ida Leyenda negra como forma de ataque a España o la, más reciente, memoria histórica como medio para dividirla. A través de estos dos personajes, como epicentro de las dos narrativas, podemos ver en sus entre líneas las características de una España imperial que se alimentaba de sus glorias pasadas, tal cual nuestro caballero andante al abrazar un ideal caballeresco ya dejado atrás varias centurias antes, y encontrar en su peculiar actualización un retrato ridículo de un pasado que ya no decía nada, si es que alguna vez lo hizo más allá de los límites de unos cantares de gesta creados con unos fines bastantes específicos para el momento en que fueron escritos. Tanto Alonso Quijano como Max Estrella añoran las delicias de un tiempo pretérito de la bohemia del que ya solo quedan recuerdos difusos que se pierden en la memoria.

Don Quijote simbólicamente metaforiza el legado de un pasado que se resiste a salir y se perpetúa a través de una idealización orgullosa que se niega a ceder. Cervantes no escatima detalles a la hora de crear ese cuadro comparativo entre su singular personaje y la glorioso España que, tanto para el autor, como para otros literatos, a la vista de sus críticas, no era tan memorable. Desde las primeras líneas del primer capítulo el autor ya deja claro que su libro no va a repetir el padrón de sus predecesores: los prodigiosos libros de caballería. En unas pocas líneas Cervantes acaba con todo aquello que el lector espera encontrar en los libros de este género tan de moda en aquellos momentos.

En un lugar de la Mancha, de cuyo nombre no quiero acordarme, no ha mucho tiempo que vivía un hidalgo de los de lanza en astillero, adarga antigua, rocín flaco y galgo corredor. Una olla de algo más vaca que carnero, salpicón las más noches, duelos y quebrantos los sábados, lentejas los viernes, algún palomino de añadidura los domingos, consumían las tres partes de su hacienda. (CERVANTES, 1998) 
La Mancha ya no es aquel lugar remoto y digno de memoria que todos los anteriores libros de caballería presentaban, ni el héroe es un valeroso y gallardo caballero, cual Amadís de Gaula, capaz de enfrentarse con toda su fuerza a una sucesión interminable de peligros sin siquiera pestañear.

-Caballero, yo os tengo por buen mancebo y os ruego que antes que más mal recibáis otorguéis ser más hermosa mi amiga que la vuestra.

—Callad —dijo Amadís-, que tal mentira nunca será por mi boca otorgada. Entonces se fueron acometer y herir con las espadas de tan fuertes golpes, que espanto ponían así a los que miraban como a ellos mismos que los recibían, considerando entre sí poderlos sufrir, mas esta batalla no pudo durar mucho, que Amadís se combatía por razón de la hermosura de su señora, donde tuviera él por mejor ser muerto que fallecer un punto de lo que debía, y comenzó a dar golpes con toda su fuerza tan duramente, que la gran sabiduría ni la gran valentía de herir de espada no le tuvo provecho a Angriote, que en poco tiempo lo sacó de toda su fuerza, y tantas veces le hizo descender la espada a la cabeza y al cuerpo, que por más de veinte lugares le salía ya la sangre; cuando Angriote se vio en peligro de muerte se tiró. afuera así como pudo, y dijo: -Cierto, caballero, en vos hay más bondad que hombre puede pensar -Otorgaos por preso -dijo Amadís-, y será vuestro provecho, que estáis tan maltratado que, habiendo la batalla fin, lo habría vuestra vida y pesarme habría de ello, que vos precio más de lo que vos cuidáis. (RODRÍGUEZ DE MONTALVO. 2014)

Para dejar claro las diferencias entre su personaje y los que le precedieron, en la construcción de su particular antihéroe, Cervantes nos revela detalles sombríos de su intimidad como sus pocos posibles y principalmente sus mermados hábitos alimenticios. Este pormenor estará, como veremos posteriormente, muy presente también en Luces de Bohemia. Aspectos como el hambre, la supervivencia, el entorno hostil y principalmente la camaradería de la pareja protagonista y su itinerante jornada aúnan las dos obras en un tipo de vía crucis que nos introduce de la mano en el contexto histórico retratado en los dos libros y nos adentran al mismo tiempo, con sus comportamientos, en una atemporalidad que traspasa los límites impuestos por el dios Cronos y el espacio al que se circunscriben estas dos creaciones literarias.

Aproximémonos ahora al contexto de la segunda obra. La literatura finisecular del XIX será la encargada de retratar, entre realidad y ficción, los principales 
acontecimientos de ese conturbado periodo de la historia fueron retratados por los muchos movimientos literarios que se sucedieron durante el siglo; desde el pensamiento ilustrado hasta la ya mencionada generación del 98. La profundidad del problema español, la sempiterna división ontológica de las dos Españas se amplificará considerablemente durante el siglo diecinueve y un acontecimiento principalmente será el detonante de las luchas internas que se sucederán en las décadas posteriores al mismo.

Aunque pueda parecer irónico fue bajo el marco de la invasión napoleónica, con el país tomado por una potencia extranjera y con las graves consecuencias de una guerra que diezmó la población, amén de otros devastadores impactos en la economía y en la sociedad, cuando los españoles, al menos una parte de ellos, tomaron contacto con su efímero sueño de libertad y aunque sin mucho efecto, gozaron de unos derechos que antes les eran negados. Desde tres perspectivas estas otras consecuencias de la ocupación pueden hoy examinarse con la neutralidad que nos ofrece la distancia temporal de más de dos siglos, la primera de ellas proviene de los sucesivos intentos del nuevo monarca José I y de su propio hermano Napoleón Bonaparte por ganarse el aprecio de los españoles. Como afirman Terrero y Regla (2003, p.244), entre las medidas tomadas por los hermanos Bonaparte estaban la supresión de la inquisición, la cual más tarde sería restaurada por Fernando VII, la reducción de parte de los numerosos conventos que diezmaban las arcas públicas, la abolición de unos vetustos derechos feudales no muy coherentes con una España que pretendía progresar e ingresar en el contexto europeo.

La segunda perspectiva se produce también en este marco de la ocupación y la subsiguiente guerra de independencia fue proclamada en 1812 en la gaditana ciudad de San Fernando la constitución liberal conocida como "la Pepa". Este documento redactado al abrigo de una ciudad sitiada que no solo fue la sede del gobierno durante la ocupación si no también el símbolo de la resistencia y el sueño de libertad. Las Cortes de Cádiz promulgaron una libertad hasta entonces desconocida para los españoles:

Todos los españoles tienen libertad de escribir, imprimir y publicar sus ideas políticas sin necesidad de licencia, revisión ó aprobación alguna anterior a la publicación, bajo las restricciones y responsabilidad que establezcan las leyes. (Art. 371) 
La tercera y últ ima perspectiva que vamos a observar sobre esta cuestión son las otras consecuencias de la ocupación francesa y su repercusión en las décadas venideras nos aproxima a un sentimiento muy conocido por los españoles desde la reconquista peninsular y enfatizado por los conocidos nacionalismos decimonónicos. Nacionalismos que la literatura y las artes en general tanto supieron aprovechar bajo un solemne lema: el patriotismo. Como diría uno de los más importantes representantes de la mencionada Generación del 98 Pio Baroja resumiendo el sentido pesimista sobre la situación española de sus compañeros, España nunca tuvo una sólida formación social y política y siempre se agitó por medio de una sucesión de convulsiones nerviosas como la que acabamos de citar líneas atrás con la invasión francesa de la península. Según el mismo autor esta actitud impulsiva y espontanea revela algo que estará muy presente en el pensamiento y en la obra de los dos autores protagonistas de esta cavilación, el desdén de un pueblo que poco se interesa por los problemas sociales que tanto les perjudican. Como diría lacónicamente Miguel de Unamuno, otro de los escritores del 98: el problema de España es que a nadie le importaba nada de nada y así lo expresaba en 1915 en su artículo La noluntad:

Que no hay conciencia nacional decimos. Ni siquiera voluntad nacional. Si la hubiera, del querer brotaría el pensar. Pero los españoles, como tales, sólo parecen querer que se les deje morir en paz. Morir, no vivir. España no quiere nada fuera de sí misma, es decir, no quiere nada. No quiere dominio territorial; no quiere dominio espiritual tampoco. Ni quiere soñar ensueños que dar a los demás. Duerme sin soñar. (...) O igo decir que el país despierta, pero lo que yo veo es que a nadie le importa nada de nada. Con dejarle a cada cual echar su partidita o lo que sea y engullir su puchero, que no le den quebraderos de cabeza «¡Déjeme usted en paz, hombre!» $Y$ en paz estamos. ¡Y tan en paz! A pesar de las apariencias en contrario. (UNAMUNO, 1915)

Al leer las palabras de Unamuno nos parece estar escuchando al propio Max Estrella y su esperpént ica visión de la España retrógrada, acomodada en una tradición de siglos pasados. 
MAX: Ilustre Don Gay, de acuerdo. La miseria del pueblo español, la gran miseria moral, está en su chabacana sensibilidad ante los enigmas de la vida y de la muerte. La Vida es un magro puchero; la Muerte, una carantoña ensabanada que enseña los dientes; el Infierno, un calderón de aceite albando donde los pecadores se achicharran como boquerones; el Cielo, una kermés sin obscenidades, a donde, con permiso del párroco, pueden asistir las Hijas de María. Este pueblo miserable transforma todos los grandes conceptos en un cuento de beatas costureras. Su religión es una chochez de viejas que disecan al gato cuando se les muere.

(VALLE INCLÁN, 2005)

Sin embargo, como ya observamos antes, el español amparándose en un ambiguo sentido patrio valora cada una de sus peculiaridades, aunque algunas de ellas hayan fomentado una visión estereotipada y en algunas ocasiones ridícula. Valle Inclán no puede dejar de observar esto con sarcasmo a la hora de referirse al controvertido tema, suscitado por Montesquieu, del clima y sus influencias en el carácter de una determinada sociedad:

DON GAY: Porque soy reumático, y me hace falta el sol de España. ZARATUSTRA: Nuestro sol es la envidia de los extranjeros.

MAX: ¿Qué sería de este corral nublado? ¿Qué seríamos los españoles? Acaso más tristes y menos coléricos... Quizá un poco más tontos... Aunque no lo creo. (VALLE INCLÁN, 2005)

\section{Dos caballeros, una misma bandera}

Aunque con trescientos años de diferencia, las dos obras, objeto de esta reflexión, nos conducen a un objetivo común por parte de los dos escritores: la denuncia social, denuncia que aparece diluida en sus páginas por medio de el peregrinaje de sus protagonistas. El particular vía crucis de ambos personajes nos sirve como un excelente recurso literario para transportarnos a los diferentes ambientes que se pretenden criticar. Por medio de esta estrategia; la sucesión de escenarios, así como el dilatado reparto de personajes variopintos nos Ilevan de la mano para observar con detalle los bast idores de la sociedad, lo más sórdido de ésta; desde el miserable despreciado por todos, hasta el mundo de las altas esferas con sus nobles y refinados usos. 
Las palabras de nuestro desfasado antihéroe, como veremos en seguida, parecen dialogar con el pensamiento de Max Estrella en muchos aspectos. Don Quijote y Sancho, Max y Don Latino, el caballero andante y su escudero son, con el beneplácito del lector, nuestros guías particulares por esta atemporalidad temática que es capaz de atravesar el tiempo y el espacio al alcanzar como la define Cándido (2006) la función total de la literatura.

A função total deriva da elaboração de um sistema simbólico, que transmite certa visão do mundo por meio de instrumentos expressivos adequados. Ela exprime representações individuais e sociais que transcendem a situação imediata, inscrevendo-se no patrimônio do grupo. Quando, por exemplo, encaramos a Odisséia, o aspecto central que fere a sensibilidade e a inteligência é esta representação de humanidade que ela contém, este contingente de experiência e beleza, que por meio dela se fixou no patrimônio da civilização, desprendendo-se da função social que terá exercido no mundo helênico. A grandeza de uma literatura, ou de uma obra, depende da sua relativa intemporalidade e universalidade, e estas dependem por sua vez da função total que é capaz de exercer, desligando-se dos fatores que a prendem a um momento determinado e a um determinado lugar. Esta função é aparentemente menos acentuada na literatura oral, que parece limitar-se ao âmbito restrito dos grupos em que atua e que a produziram. Todavia, quando surgem possibilidades de comunicação entre os grupos, a sua universalidade pode afirmar-se, e até em que mais do que sucede com as obras da literatura erudita, - pois se de um lado ela radica em experiências peculiares ao grupo, de outro encarna certos temas da mais acentuada intemporalidade, como os de alguns mitos, análogos em vários povos. (CÁNDIDO, 2006)

Esta función total nos permite acceder a los vericuetos del alma humana y las narraciones tienen el poder de llegar a todo tipo de público independiente de su procedencia o de la época en que fueron redactadas. El formato narrativo de ambas obras, el diálogo, nos aproxima aún más a la historia y a veces pareciese que los personajes nos están hablando y aconsejándonos como si fuésemos nosotros también sus otros compañeros de viaje. No son solo Sancho y Don Lat ino los que escuchan los proverbiales consejos de Don Quijote y de Max Estrella.

La libertad, Sancho, es uno de los más preciosos dones que a los hombres dieron los cielos; con ella no pueden igualarse los tesoros 
que encierra la tierra ni el mar encubre; por la libertad, así como por la honra se puede y debe aventurar la vida, y, por el contrario, el cautiverio es el mayor mal que puede venir a los hombres. (CERVANTES, 1998)

La España del Siglo de Oro o la de la Restauración nos son indiferentes cuando llevamos la denuncia social a un grado superior, a un punto en que los detalles históricos son eso, tan solo detalles y no nos importan ni fechas ni lugares. La literatura, como observaba Cándido, alcanza así su atemporalidad.

\section{Los puntos en común}

Una vez visitado el contexto, vamos a mostrar los puntos sobre los que se basa nuestra argumentación a la hora de examinar Luces de Bohemia desde la perspectiva de una relectura moderna del Quijote por parte de su autor Ramón del Valle Inclán. Antes de comenzar la descripción de los aspectos en común entre ambas obras es importante resaltar que a la luz de críticos como Francisco Rico (1998), organizador de una de las ediciones críticas más completas de la magistral obra cervantina, el tema quijotesco fue muy prolífico para esta generación finisecular y prácticamente todos los autores publicaron algún estudio sobre dicha obra. En un corto espacio tiempo vieron la luz obras tan importantes como Vida de Quijote y Sancho de Miguel de Unamuno de 1905, autor que dedicará numerosos artículos al mismo tema. Ese mismo año Azorín publica La ruta de Quijote como una forma de prestigiar la tierra castellana, a la que su generación le dedicó tantas páginas. Ramiro de Maeztu, integrante con Azorín y Baroja del pionero Grupo de los tres, escribió varios textos sobre el tema años más tarde juntará todos ellos en su libro Don Quijote, Don Juan y Celestina (1919). En 1914 Ortega y Gasset también visitará el tema y publica Las Meditaciones del Quijote, libro que a pesar de que su autor no pertenece al cuadro de autores de la dicha generación de final de siglo, nos ofrece una visión muy particular de la situación por la que pasaba España y confronta amargamente las dos épocas que aquí estamos visitando.

Es, por lo menos, dudoso que haya otros libros españoles verdaderamente profundos. Razón de más para que concentremos 
en el Quijote la magna pregunta: Dios mío, ¿qué es España? En la anchura del orbe, en medio de las razas innumerables, perdida entre el ayer ilimitado y el mañana sin fin, bajo la frialdad inmensa y cósmica del parpadeo astral, ¿qué es esta España, este promontorio espiritual de Europa, esta como proa del alma continental? ¿Dónde está-decidme-una palabra clara, una sola palabra radiante que pueda satisfacer a un corazón honrado y a una mente delicada, una palabra que alumbre el dest ino de España? (ORTEGAY GASSET)

Vamos ahora a ver los aspectos coincidentes sobre los que basamos nuestra argumentación:

\section{1 La presencia de una pareja protagonista como motor de la narrativa}

La jornada emprendida por las dos parejas protagonistas, la presencia constante del dialogo entre ellos y con los personajes secundarios que van apareciendo a lo largo de las páginas nos ayudan a trazar un retrato nítido de la sociedad de la época. Retrato este que es esbozado a partir del contraste de visiones de mundo que nos presentan cada uno de los personajes protagonistas. Esta representación, como ya fue observado anteriormente, nos permite pasar de un mundo idealizado, a veces utópico, a los bastidores de un mundo sórdido que se mueve por el interés y cuyos valores están muy distantes del ideal promovido por el caballero andante y por el poeta invidente, que como el ciego de El Lazarillo de Tormes, no precisa la visión para tener una imagen límpida de los vicios de un mundo decadente.

En ambas obras, a través del diálogo constante entre los dos protagonistas, se nos permite conocer a fondo el contexto de la época y cómo se va construyendo, como va evolucionando la fraternal relación entre los dos personajes. Por medio del diálogo, podemos observar y reflexionar, junto a los personajes, sobre determinados asuntos que, por su universalidad, conciernen a todos los lectores, tales como: la amistad, la libertad y la lealtad. (LÓPEZ, 2015)

Al leer esta cita no nos resulta fácil distinguir si ésta hace referencia a la obra cervantina o a Luces de bohemia: amistad, libertad y lealtad son valores muy 
presentes en los dos libros y son precisamente estos los que la han dado a ambas obras su atemporalidad.

\subsection{El espíritu de denuncia social}

Con el fondo del esperpento, el autor gallego realiza, al igual que en la obra cervantina, una fuerte crítica social. Cabe, si acaso, a Max Estrella la invectiva más incisiva y directa sobre la sociedad de su tiempo. La postura, por otro lado, del caballero andante, quien de la mano de su autor y mediando juegos retóricos de persuasión nos sitúa frente a cada una de las situaciones que pretende criticar para que seamos nosotros, sus lectores, quienes completemos el sentido de sus palabras, difiere de la de Valle Inclán No es preciso ser, como diría Borges, un lector muy atento para percibir el objetivo perseguido por Cervantes a la hora de alabar las dichas del mundo clásico, examinadas desde el contexto del mundo que le tocó vivir.

Dichosa edad y siglos dichosos aquellos a quien los antiguos pusieron nombre de dorados, y no porque en ellos el oro (que en nuestra edad de hierro tanto se estima) se alcanzase en aquella venturosa sin fatiga alguna, sino porque entonces los que en ella vivían ignoraban estas dos palabras de tuyo y mío. Eran en aquella santa edad todas las cosas comunes; a nadie le era necesario para alcanzar su ordinario sustento tomar otro trabajo que alzar la mano y alcanzarle de las robustas encinas, que liberalmente les estaban convidando con su dulce y sazonado fruto... (CERVANTES, 1998)

A través de la visión de Max Estrella la denuncia se presenta, aunque con un tono sarcástico, de forma más explícita.

MAX: ¡Ya se guardará usted del intento! ¡Soy el primer poeta de España! ¡Tengo influencia en todos los periódicos! ¡Conozco al Ministro! ¡Hemos sido compañeros!

SERAFÍN EL BONITO: EI Señor Ministro no es un golfo.

MAX: Usted desconoce la Historia Moderna.

(VALLE INCLÁN, 2005)

A través del preso que Max encuentra en su prisión temporaria la voz del autor se hace aún más incisiva y proclama la acción directa como única alternativa. Como lo 
hace Don Quijote, es necesario salir y defender las injusticias desde donde éstas ocurren y no desde el campo de las ideas exclusivamente.

EL PRESO: No basta. El ideal revolucionario tiene que ser la destrucción de la riqueza, como en Rusia. No es suficiente la de todos los ricos. Siempre aparecerá un heredero, y aun cuando se suprima la herencia, no podrá evitarse que los despojados conspiren para recobrarla. (VALLE INCLÁN, 2005)

\subsection{La presencia de una deficiencia}

La ceguera de Max Estrella y la locura como recursos literarios nos ayudan a ver el mundo desde otra perspect iva diferente de la habitual. Independiente de las posibles simbologías por detrás de estas deficiencias, las dos permiten a los autores la distorsión de la realidad para adecuarla a una visión acida y muchas veces mordaz del mundo. La locura y la ceguera, conducen a los dos protagonistas a un estado de enajenación, de lucida locura que les abre, que nos abre la puerta de la percepción de una realidad atroz; un mundo de injusticia, de corrupción en el que constantemente se invierten los valores morales.

MAX: El ciego se entera mejor de las cosas del mundo, los ojos son unos ilusionados embusteros. (VALLE INCLÁN, 2005)

\section{4 La muerte y la vuelta de la consciencia}

La muerte y la vuelta a la cordura se hace presente en las dos obras como una forma de retorno a la realidad, aunque ésta se manifieste de formas diferentes en cada uno de los dos personajes principales. Para nuestro caballero andante los momentos que anteceden a su muerte vienen acompañados de una clarividencia que le devuelve a su punto de origen. Muere Don Quijote, pero quien toma conocimiento de esta próxima defunción es Don Alonso Quijano, un hidalgo algo fantasioso que en su transitoria enajenación adaptó una nueva personalidad, una mezcla inusitada de tragedia y humor, de locura y de lucidez. 
QUIJOTE: yo fui loco, y ya soy cuerdo; fui don Quijote de la Mancha, y soy agora, como he dicho, Alonso Quijano el Bueno.

(CERVANTES, 1998)

Para Max Estrella, la muerte viene antecedida por la visión recobrada, una luz que le devuelve a los tiempos áureos de la bohemia parisiense, en la cual el mismo preside su entierro. Son éstas sus Luces de bohemia, una lúcida locura que le permite asistir, al igual que Alonso Quijano, a su propia muerte. Max preside su propio entierro.

MAX: Latino, me parece que recobro la vista. ¿Pero cómo hemos venido a este entierro? ¡Esa apoteosis es de París! ¡Estamos en el entierro de Víctor Hugo! ¿Oye, Latino, pero cómo vamos nosotros presidiendo? (VALLE INCLÁN, 2005)

\subsection{El carácter itinerante}

La libertad dada por sendos autores a sus protagonistas y el carácter it inerante de la trama les permiten llevar a sus personajes a pasear por los diferentes cuadros sociales que pretenden criticar: la España imperial de los siglos XVIY XX. Como si de una cámara escondida se tratase, nos adentramos en los bastidores de una sociedad decadente que se opone a la esperpént ica visión del Caballero andante y del Poeta. Es precisamente este paisaje con figuras y lugares reconocibles por el lector en su viaje a través de las páginas de ambos libros el que les otorga su realismo y la distancia frente a la fantasía desmedida que se había apoderado de los libros de caballería o de la estética modernista que sobreponía la forma sobre el fondo, al mensaje y su extraordinaria capacidad de denuncia. Al caminar con ellos sent imos que el mundo tal y como lo conocemos se tambalea y se deforma.

MÁXIMO ESTRELLA y DON LATINO DE HISPALIS tambalean asidos del brazo por una calle enarenada y solitaria. Faroles rotos, cerradas todas, ventanas y puertas. En la llama de los faroles un igual temblor verde y macilento. La luna sobre el alero de las casas, partiendo la calle por medio. De tarde en tarde, el asfalto sonoro. Un trote épico. Soldados Romanos. Sombras de Guardias: Se extingue el eco de la patrulla. La Buñolería Modernista entreabre su puerta, y una banda de luz parte la acera. MAX y DON LATINO, borrachos lunáticos, 
filósofos peripatéticos, bajo la línea luminosa de los faroles, caminan y tambalean. (VALLE INCLÁN, 2005)

\section{Consideraciones finales}

Leer un libro es abrir una puerta, puerta que a su vez se abre a otras que son las diferentes perspectivas desde las cuales podemos abordar la lectura de este libro y así de acuerdo con nuestra interpretación personal de la obra literaria, esta metáfora puede convert ir la casa a la que accedemos al entrar por esa primera puerta en una mansión con un sinnúmero de otras puertas. Siendo así, sí la obra literaria nos permite un universo de lecturas, de múltiples interpretaciones de acuerdo con la consideración de aspectos tales como nuestra propia visión, el contexto socio histórico en el cual la obra fue leída o tantos otros aspectos. Nos preguntamos entonces; porqué debemos enclaustrar una obra dentro de una serie de característ icas que la confinan y le anulan su capacidad de transmitir, como cualquier otra obra artística, un mundo infinito de sensaciones, de posibles y enriquecedoras relecturas. Nos propusimos aquí, a través de la relectura de estas dos obras, rescatar la esencia de cada una de las creaciones literarias para mostrar que ese confinamiento al que hacíamos referencia hace poco, herencia de un decimonónico positivismo, termina por anular la aproximación del lector a la literatura como hecho literario y $\tan$ solo le permite llegar elementos periféricos de ésta como la importancia del autor dentro de la historia de la literatura, sus principales obras y en muchos casos, principalmente cuando se trata de autores actuales y más mediáticos, de aspectos biográficos que poca y ninguna relación guardan con su creación artística son actualmente los valores crít icos que prevalecen.

Don Quijote y Max Estrella van mucho más allá de la imagen idealizada que de ellos ha creado el mercado. Un mercado más preocupado en forjar el semblante de estos dos personajes desde la irreverencia, desde la inadaptación que los convierte en notas disonantes dentro de una sociedad reglada y maquiavélicamente arreglada. Una sociedad que convierte el deseo de un mundo mejor en una locura digna de nuestra pena o por lo menos de nuestro desdén. Como ya observamos anteriormente, personajes como Don Quijote y Max Estrella revelan a través de su mirada destorcida de la realidad que es posible ver el mundo desde otra perspectiva, que es posible 
cambiar las cosas, que es posible escapar de nosotros mismos para buscar nuevas metas, nuevos objetivos sin que eso convierta nuestros sueños, nuestros anhelos en algo quijotesco. Existe un Max Estrella dentro de Don Quijote y existe un Don Quijote dentro de Max Estrella. La locura y la ceguera se hermanan para mostrarnos que no toda la realidad es real y tampoco todo lo que nuestros ojos pueden ver es lo que realmente vemos. Los espejos del Callejón del gato que según Valle Inclán mostraban la deformación grotesca de la cultura europea son reminiscencias de la visión quijotesca de un mundo en decadencia:

MAX: Los héroes clásicos reflejados en los espejos cóncavos dan el Esperpento. El sentido trágico de la vida española sólo puede darse con una estética sistemáticamente deformada. (VALLE INCLÁN, 2005)

\section{Referencias bibliográficas}

BLANCO AGUINAGA, C.; ZAVALA, I.M.; RODRÍGUEZ PUÉRTOLAS, J. Historia social de la literatura española (en lengua castellana). 3 Vols. Madrid: Ed. Castalia, 1979.

CÂNDIDO, A. Literatura e Sociedade. Rio de Janeiro: Ed. Ouro sobre azul, 2006.

CERVANTES, M. Don Quijote de la Mancha. Barcelona: Ed Óptima, 1998.

COMPAGNON, A. O demônio da teoria. Literatura e senso comum. Belo Horizonte: Ed. UFMG, 2003.

Constitución de Cádiz. Edición digital disponible en: http:/www.congreso.es/portal/page/congreso/congreso/Hist_normas/constesp/1812_1978/c onst1812 Acceso en: 26 jul. 2018.

ELLIOT, J. El viejo mundo y el nuevo. 1492-1650. Madrid: Alianza Editorial, 1979.

LOPÉZ, J. I. J.C. Os franciscanos na Nova Espanha: crónica de uma experiencia humanista através de seu epistolário. 1523-1583. Recife: Ed. Universitaria UFPE, 2015.

ORTEGA Y GASSET, J. Meditaciones del Quijote. Disponible en: http://www.mercaba.org/SANLUIS/Filosofia/autores/Contempor\%C $3 \%$ A1nea/Ortega\%2oy \%20Gasset/Meditaciones\%20del\%20Quijote.pdf Acceso en: 25 set. 2018

PASCUAL, P. El 98 de Don Quijote. Actas del VIII Congreso de la Asociación Internacional de Cervantistas. Disponible en: https://cvc.cervantes.es/literatura/cervant istas/coloquios/cl VIII/cl VIII_13.pdf Acceso en: 25 set. 2018. 
POLAR, A.C. O condor voa. Belo Horizonte: Ed. UFMG, 2000.

RODRÍGUEZ DE MONTALVO, G. Amadís de Gaula. Barcelona: Linkgua Ediciones, 2014.

TERRERO, J. REGLA, J. Historia de España. De la Prehistoria a la actualidad. Barcelona: Ed. Óptima, 2003.

TODOROV, T. La conquista de América. El problema del otro. México D.F: Siglo XXI, 2007.

UNAMUNO, M. La noluntad. España. Semanario de la vida nacional, n. 8, v. 1 Madrid, viernes 19 de marzo de 1915. Disponible en: http://www.filosofia.org/hem/dep/esp/9150319c.htm. Acceso en: 25 set 2018.

' Doutor em Letras pela Universidade Federal de Pernambuco (UFPE). Professor da Universidade Federal da Paraiba (UFPB).

juanig@terra.com.br 